\title{
PEMBIASAAN MEDITASI PADA SISWA SEKOLAH DASAR BERCIRI BUDDHIS DI JAKARTA DAN TANGERANG
}

\author{
Sugianto \\ Sekolah Tinggi Agama Buddha Negeri Sriwijaya Tangerang Banten \\ sugianto@stabn-sriwijaya.ac.id
}

\begin{abstract}
Habituation of meditation is the characteristic of Buddhist education. The purpose of these research to describe the introduction and the habituation of meditation, techniques and objects meditation in the elementary Buddhis school. This is a descriptive qualitative research. Research sites in Jakarta and Tangerang from July to December 2017. Data collection by interview and documentation. The validity data with test credibility, dependability, confirmability, and transferbility. Data analysis using models of Miles $\&$ Huberman. The results of research is: introduction of meditation is a program derived from the policy of foundation, principal of school or Buddhist religion teacher; practice of meditation is regularly everyday or everyweek; Buddhist religion teachers become direct guides; the practice of meditation is done in class, cetiya, Dhamma class room, hall, or school yard; student concentrate on the object of meditation or listening positive sentences; meditation duration between 3 - 15 minutes according to grade level and meditation objectives. The teacher use an audio meditation guide, music instrument, bell, slide picture. Object meditation is breathing, lovingkindness, and contemplation.

Keywords: The Introduction of meditation, the habituation of meditation,

Buddhis education, students of elementary Buddhis schools
\end{abstract}

\section{A. Pendahuluan}

Sekolah adalah pusat pendidikan formal yang menyelenggarakan pendidikan atau pembelajaran mengacu pada standar pendidikan nasional. Selain itu, dengan adanya manajemen berbasis sekolah, sekolah mengemas program pendidikan secara khas. Oleh karena itu sekolah memiliki kewajiban untuk memenuhi standar nasional pendidikan sekaligus berkesempatan mengembangkan program yang menjadi ciri khas sekolah, misalnya sekolah berciri Buddhis memiliki penguatan nilai-nilai karakter melalui pendidikan keagamaan Buddha.

Penguatan nilai-nilai karakter Buddhis menjadi bagian penting dalam pembelajaran pendidikan agama Buddha. Pendidikan Agama Buddha tidak hanya terfokus pada penyampaian ilmu agama, tetapi ada proses pembentukan karakter. Karakter siswa yang dibangun, antara lain religius, jujur, toleransi, cinta damai, dan tanggung jawab. Pembangunan karakter siswa terutama pada sikap spiritual dikembangkan dengan pembiasaan-pembiasaan aktivitas keagamaan Buddha. 
Mengenalkan meditasi kepada siswa merupakan hal yang sangat positif. Guru membimbing anak belajar fokus atau menenangkan pikiran, melatih kesadaran dan perhatian pada segala aktivitas di sekolah. Meditasi dirancang dengan memperhatikan kebutuhan dan perkembangan siswa. Beberapa sekolah beryayasan Buddhis di Jakarta dan Tangerang telah menyelenggarakan kegiatan meditasi bagi siswa secara rutin, antara lain di Sekolah Dasar Insan Teratai disebut Silent Sitting atau duduk hening, di Sekolah Dasar Atisa Dipamkara diadakan di awal pembelajaran dan pada saat Dhammaclass, di Sekolah Dharma Putra diselenggarakan setiap hari. Sekolah beryayasan Buddhis berkewajiban menjaga dan melestarikan budaya meditasi yang benar. Tujuan dari penelitian ini adalah mendeskripsikan bentuk pembiasaan meditasi kepada siswa sekolah dasar.

Kontribusi penelitian ini: (1) Secara teoretis akan menambah pengetahuan tentang bentuk pembiasaan meditasi bagi siswa di sekolah dasar; (2) Secara praktis, hasil dari penelitian ini dapat dimanfaatkan: (a) Bagi pimpinan lembaga pendidikan beryayasan Buddhis sebagai dasar kebijakan penyelenggaraan program meditasi di sekolah; (b) Bagi guru dijadikan rujukan dalam menerapkan kegiatan pembiasaan meditasi kepada siswa; (c) Bagi perguruan tinggi keagamaan Buddha dapat mengembangkan program mata kuliah yang mengarah pada pengembangan keahlian mahasiswa agar memiliki kompetensi membimbing meditasi; (d) Bagi mahasiswa, dapat dijadikan dasar penyiapan kompetensi sebagai pemandu kegiatan meditasi pada siswa sekolah dasar; (e) Bagi masyarakat dapat menjadi cara untuk membudayakan latihan meditasi; (f) Bagi peneliti lain, dapat dilanjutkan dengan penelitian yang sejenis atau lanjutan.

\section{Meditasi Buddhis}

Meditasi dalam bahasa Pali adalah bhāvanā memiliki beberapa arti yaitu: producing, dwelling on something, putting one's thoughts to, application, developing by means of thought or meditation, cultivation by mind, culture. Meditasi diartikan sebagai mengembangkan, meninggalkan sesuatu, mengarahkan pikiran, penerapan, mengembangkan pikiran atau meditasi, pengembangan pikiran, dan pembudayaan (Davids, 2009: 559).

Menurut Vijja-Bhagiya Sutta, Anguttara Nikaya bagian Duka Nipata (AN 2.30) ada dua cara untuk mengembangkan pengetahuan yang murni yaitu dengan tranquillity (samatha) $\mathcal{E}$ insight (vipassana). Ketenangan (samatha) dilakukan untuk menuju pengembangan pikiran yang akan membuat nafsu keinginan ditinggalkan. Pandangan terang (vipassana) dilakukan dengan tujuan untuk mencapai ketajaman pikiran sehingga ketidaktahuan dilenyapkan (Thanisaro, 1998).

Praktik meditasi Buddhis dilakukan bukan semata-mata untuk mencapai pemahaman intelektual, tetapi lebih dari itu untuk mencapai pembebasan, membebaskan diri dari khayalan dan mengakhiri penderitaan dan keinginan. The purpose of Buddhist meditation, therefore, is to gain more than an intellectual 
understanding of this truth, to liberate ourselves from the delusion and thereby put an end to both ignorance and craving (Francis Story, 1995).

Burns (1994) menyatakan bahwa tujuan tertinggi dari praktik meditasi Buddhis adalah untuk menghentikan dukkha dan merealisasikan nibbana. Selain itu, ada manfaat nyata yang dapat dirasakan dalam kehidupan sehari-hari dalam peningkatan, pengembangan, dan pengolahan perasaan-perasaan positif seperti cinta kasih, kasih sayang, simpati, dan keseimbangan batin; ajaran Buddha menyarankan pada pelepasan atau penolakan keserakahan, kebencian, kebodohan, kesombongan, iri hati, dan faktor-faktor batin buruk lainnya.

Menurut Shaw (2006), bahwa pikiran manusia mampu mengembangkan segala hal yang dibutuhkan melalui pengembangan diri. ... the human mind can produce all the reserves it needs through self-development. Pengembangan diri secara batiniah berpotensi menciptakan segala hal yang diharapkan.

Buddhaghosa (Nanamoli, 2011: 86) menjelaskan beberapa hal yang perlu dilakukan agar konsentrasi dapat berkembang dengan baik. Hal yang pertama dilakukan adalah untuk mengembangkan konsentrasi orang mengambil sila atau bertekad menjalani kehidupan moralitas, selanjutnya 10 hambatan meditasi diputuskan. Kemudian mendekati teman yang baik, memilih salah satu dari 40 objek meditasi yang sesuai dengan karakter, menghindari pola hidup yang tidak mendukung pengembangan konsentrasi, dan tinggal di tempat yang cocok untuk meditasi.

Meditasi merupakan ajaran pokok dalam Buddhisme. Meditasi dipraktikkan dengan cara mengolah batin untuk mencapai konsentrasi, ketenangan atau pandangan terang. Tujuan tertinggi dari meditasi Buddhis adalah mengatasi dukkha. Agar meditasi dapat terlaksana dengan baik, dibutuhkan perilaku bermoral, kemampuan mengatasi gangguan meditasi, dan pemilihan objek meditasi yang tepat.

Sekolah

Lingkungan sekolah yang baik memenuhi standar lingkungan fisik dan lingkungan psikososial. Menurut Notoatmodjo (2012) lingkungan fisik memiliki standar antara lain: mampu menyediakan kebutuhan dasar dan insan sekolah lain; Mampu melindungi insan sekolah dari ancaman penyakit; Mampu melindungi insan sekolah dari ancaman biologis; dan Mampu melindungi insan sekolah dari ancaman kimiawi. Sedangkan lingkungan psikososial sekolah harus dapat memenuhi kebutuhan psikologi siswa di antaranya: iklim belajar dan kerja sama yang baik; rasa keterikatan sesama insan sekolah; rasa saling menghargai; dan perlindungan terhadap kekerasan.

\section{Siswa Sekolah Dasar}

Sekolah memiliki tanggung jawab untuk mendidik siswa agar memiliki pengetahuan luas tentang berbagai ilmu pengetahuan di antaranya pendidikan agama Buddha. Sekolah juga menjadi tempat melatih keahlian siswa sesuai dengan bidang ilmu yang diajarkan. Selain itu, sekolah juga menjadi tempat untuk membentuk karakter siswa yang beretika. Siswa yang beretika akan 
memberi dampak yang positif bagi diri sendiri atau orang lain yaitu hidup yang bahagia dan sejahtera seperti yang tercantum dalam Maha Manggala Sutta, Khuddakapatha, Khuddaka Nikaya (Lay, 2000: 2016).

Berdasarkan ciri-ciri biologis, siswa sekolah dasar menurut Aristoteles masuk dalam kategori fase anak sekolah atau masa belajar (antara 7 - 14 tahun) tumbuh gigi baru, timbul gejala berfungsinya kelenjar-kelenjar kelamin. Menurut Freud anak sekolah dasar berada pada fase laten, anak tampak tenang; desakan seksual mulai mengendur dengan mengalihkan pada masalahmasalah sekolah dan teman sejenisnya. Montessori menjelaskan bahwa anak usia sekolah dasar berada pada periode II ( 7 - 12 tahun) pada periode abstrak, anak mulai menilai perbuatan manusia atas dasar baik dan buruk dan mulai timbul insan kamil (Desmita, 2010: 20 - 22).

Berdasarkan aspek didaktis, Comenius berpendapat anak pada usia sekolah dasar (6 - 12 tahun) merupakan masa mengembangkan daya ingat pikiran dan mulai diajarkan bahasa ibu atau vernacular. Dari aspek psikologi, Kroch berpendapat bahwa anak usia 3 - 12 tahun disebut fase keserasian sekolah, pada akhir masa ini anak mengalami sifat trotz kedua yaitu kebiasaan suka membantah atau menentang terutama pada orangtua yang didasarkan pada sifat berpikir yang lebih maju dari pada orang lain dan keyakinan yang dianggap benar. Dari segi perkembangan, Havighrust menyatakan bahwa anak usia sekolah dasar yaitu 6 - 12 tahun sudah memahami konsep yang diperlukan untuk berpikir efektif; mengembangkan kata hati, moral dan nilai, dan mencapai kemandirian pribadi (Desmita, 2010: 23-25).

Sesuai dengan fase perkembangan anak usia sekolah dasar, ada beberapa hal yang menjadi kebutuhan siswa di sekolah yaitu kebutuhan jasmaniah, kebutuhan rasa aman, kebutuhan akan kasih sayang, kebutuhan akan penghargaan, kebutuhan akan rasa bebas, dan kebutuhan rasa sukses (Desmita, 2010: 67-72). Sekolah memiliki kewajiban untuk memenuhi kebutuhaan siswa melalui penyediaan sarana dan prasarana penunjang pembelajaran dan model pembelajaran yang diterapkan di sekolah menjadi sarana pemenuhan kebutuhan siswa.

Seiring dengan perkembangan fisik dan mental, siswa mulai mengenali diri sendiri dengan mengetahui cara kerja pikiran. Pengetahuan berguna untuk menentukan strategi siswa dalam melakukan berbagai aktivitas, karena terkandung komponen perencanaan, pelaksanaan dan evaluasi. Ferari dan Stenberg dalam Desmita menyebutkan bahwa model sintesis metakognitif mencoba mengoordinasikan pengetahuan metakognitif dengan aktivitas kognitif. Pengetahuan metakognitif menurut Flavell dalam Desmita (2010: 134) mengandung tiga komponen yaitu variabel diri, variabel tugas, dan variabel strategi. Variabel diri berarti pengetahuan tentang person (diri sendiri dan orang lain); variabel tugas adalah pengetahuan terhadap tugas-tugas yang harus dikerjakan; variabel strategi adalah pengetahuan tentang strategi dalam mengatasi permasalahan. Aktivitas metakognitif menurut Baker dalam Desmita (2010: 134) mencakup usaha-usaha siswa dalam memonitor, 
mengontrol, dan menyesuaikan proses kognisi dalam merespon tuntutan tugas atau kondisi.

Perkembangan aspek moral anak usia sekolah dasar menurut Freud dipengaruhi oleh id, ego, dan superego. Id merupakan struktur kepribadian yang terdiri dari aspek biologis yang irasional dan tidak disadari. Ego adalah aspek keperibadian yang terdiri dari aspek psikologi, yang rasional, disadari, tapi tidak didasarkan pada moralitas. Superego adalah struktur kepribadian yang terdiri dari aspek sosial yang berisikan nilai dan moral yang sangat memperhitungkan benar atau salah suatu tindakan (Desmita, 2010: 258).

Menurut Piaget pada usia 6-9 tahun, anak mengalami heteronomous morality atau morality constraint yaitu menganggap bahwa ketentuan-ketentuan yang dibuat oleh orang yang dihormati dianggap suci dan tidak dapat diubah, dan bila dilanggar maka ada hukuman. Pada usia 9-12 tahun anak sedang mengalami autonomous morality atau morality of cooperation yang artinya anak sudah mengetahui bahwa aturan dibuat oleh manusia dan untuk menilai tindakan mempertimbangkan maksud dan akibatnya; peraturan berkaitan dengan kenyamanan dan kontrak sosial yang disetujui bersama sehingga menerima perubahan bila didasarkan kesepakatan; anak lebih menghormati teman sebaya dibandingkan orangtua (Desmita, 2010: 260).

Pada aspek spiritualitas, perkembangan spiritual siswa menurut Fowler dalam Desmita (2010: 279) pada usia 7-11 tahun berada pada tahap mythicliteral faith, yakni anak mulai mengambil makna dari tradisi masyarakatnya; naratif atau cerita menjadi orientasi pokok pada tahap ini karena cerita sebagai sarana utama menyatukan dan menilai pengalaman. Implikasi dari perkembangan moral dan spiritual bagi sekolah antara lain: memberikan moral dan keagamaan melalui kurikulum tersembunyi; memberikan pendidikan moral langsung; memberikan pendekatan moral melalui klarifikasi nilai; menjadikan pendidikan sebagai wahana kondusif untuk menghayati agamanya; membantu siswa mengembangan rasa ketuhanan dengan pendekatan spiritual parenting (Desmita, 2010: 286 - 287).

Berdasarkan pendapat di atas, pendidikan yang mengarah pada pengembangan etika siswa sangat dibutuhkan. Dalam penyelenggaran pendidikan bagi siswa sekolah dasar, guru harus mempertimbangkan karakteristik siswa yang memiliki kebutuhan pendidikan yang khas sesuai dengan fase perkembangan siswa.

\section{B. Metode Penelitian}

Penelitian ini termasuk jenis penelitian deskriptif kualitatif. Peneliti mendeskripsikan bentuk kegiatan pembiasaan meditasi, teknik dan objek meditasi yang digunakan pada siswa sekolah dasar. Pendekatan yang digunakan adalah fenomenologi. Penelitian dilaksanakan di beberapa sekolah dasar beryayasan Buddhis di Tangerang dan Jakarta yaitu SD Atisa Dipamkara, SD Dharma Putra, SD Insan Teratai, SD Mutiara Bangsa, SD Sinar Dharma, dan SD Tri Ratna. Waktu penelitian dimulai pada bulan Juli sampai dengan Desember 2017. Teknik pengumpulan data dengan menggunakan 
wawancara, dan dokumentasi. Untuk menguji keabsahan data dilakukan dengan uji kredibilitas, dependabilitas, konfirmabilitas, dan transferbilitas hasil penelitian. Analisis data menggunakan teknik Miles dan Huberman bahwa analisis dilakukan secara interaktif dan berlangsung terus menerus sampai tuntas, sehingga datanya jenuh mulai dari tahap pengumpulan data, tahap reduksi data, tahap data display, dan tahap verifikasi.

\section{Hasil dan Pembahasan}

Program Meditasi

Kepala SD Insan Teratai di Tangerang, Kepala SD Dharma Putra di Tangerang dan Kepala SD Sinar Dharma di Tambora Jakarta membuat kebijakan program meditasi di sekolah. Pembuat kebijakan penyelenggaraan kegiatan meditasi di SD Atisa Dipamkara adalah kepala sekolah yang diketahui oleh Yayasan. Guru Pendidikan Agama Buddha di SD Mutiara Bangsa di Tangerang, SD Tri Ratna di Jakarta menjadi pihak yang membuat kebijakan kegiatan meditasi di sekolah khususnya pada pelajaran PAB.

SD Insan Teratai di Tangerang memberikan nama kegiatan meditasi dengan silent sitting atau duduk hening dengan mendengarkan panduan meditasi dan musik instrumen meditasi. Duduk hening yang ada di SD Sinar Dharma dilakukan siswa sambil mendengarkan kata-kata positif yang disusun oleh guru-guru di Sekolah Sinar Dharma. Kegiatan meditasi di SD Tri Ratna menurut Kepala Sekolah disebut duduk hening, lebih lanjut guru Pendidikan Agama Buddha di sekolah tersebut menyatakan kegiatan meditasi berintegrasi dengan kegiatan baca paritta dan pembelajaran. Sementara guru Pendidikan Agama Buddha di SD Mutiara Bangsa menyatakan bahwa meditasi menjadi kegiatan yang terintegrasi dengan pembelajaran PAB di kelas, khusus pada kelas enam meditasi menjadi bagian dari praktik pembelajaran karena ada materi belajar tentang meditasi.

Kepala SD Dharma Putra, SD Sinar Dharma bertanggun-jawab atas penyelenggaraan kegiatan meditasi di sekolah. Guru piket menjadi pihak yang bertanggung-jawab dalam kegiatan silent sitting di SD Insan Teratai. Guru Pendidikan Agama Buddha di SD Mutiara Bangsa bertanggung-jawab dalam kegitan meditasi di sekolah. Di SD Atisa Dipamkara tanggung jawab secara umum kegiatan meditasi adalah yayasan yang selanjutnya diturunkan ke kepala sekolah, dan secara teknis tanggung jawab kegiatan meditasi adalah guru Pendidikan Agama Buddha.

Program meditasi di SD Sinar Dharma dilaksanakan baru dua tahun, SD Insan Teratai menyelenggarakan kegiatan meditasi sekitar lima tahun lalu, dan SD Dharma Putra Tangerang menyelenggarakan kegiatan meditasi untuk siswa sejak tahun 2007.

\section{Pembiasaan Meditasi}

Ada beberapa cara yang dilakukan guru maupun sekolah dalam membiasakan meditasi. SD Atisa Dipamkara, pada awal tahun pembelajaran mengundang orangtua atau wali dalam bentuk forum rapat wali murid dan memberitahukan tentang kegiatan meditasi yang akan dilakukan oleh seluruh 
siswa. Pembiasaan meditasi pada siswa dengan menggunakan objek meditasi pernafasan sebagai objek meditasi universal dan lebih dipahami oleh seluruh siswa baik yang beragama Buddha maupun non Buddha. Kegiatan meditasi diawali dengan membaca doa sesuai dengan keyakinan masing-masing.

SD Putra, SD Insan Teratai, SD Atisa Dipamkara, SD Sinar Dharma, dan SD Tri Ratna menyelenggarakan meditasi untuk siswa setiap hari, sedangkan SD Mutiara Bangsa menyelenggarakan meditasi tiap minggu. Waktu meditasi di sekolah bervariasi yaitu ketika pembelajaran akan dimulai pukul 6.45-07.00, ketika pembelajaran $\mathrm{PAB}$ akan dimulai, saat akan istirahat, dan saat praktik pelajaran PAB. SD Insan Teratai, SD Tri Ratna, SD Sinar Dharma, dan SD Putra selalu mengawali kegiatan pembelajaran dengan meditasi secara bersama-sama atau masing-masing kelas. SD Sinar Dharma memiliki waktu meditasi khusus untuk siswa-siswa yang butuh bimbingan dan konseling, yaitu mulai pukul 06.45 s.d. 07.00. Di SD Mutiara Bangsa dilakukan meditasi saat akan pembelajaran Pendidikan Agama Buddha. SD Atisa Dipamkara melaksanakan meditasi saat ada kegiatan Dhamma Class. Ada juga sekolah-sekolah yang melakukan meditasi lebih dari sekali, yaitu SD Dharma Putra selain diawal pembelajaran di pagi hari, juga saat akan belajar Pendidikan Agama Buddha dan saat istirahat juga dilaksanakan meditasi. Hal yang sama juga dilakukan di SD Tri Ratna, guru PAB mengajak siswa bermeditasi saat akan belajar Pendidikan Agama Buddha.

Praktik meditasi yang terus menerus dilakukan oleh siswa diharapkan mampu mengembangkan ketenangan dan konsentrasi bagi siswa. Batin yang tenang dibutuhkan siswa agar mampu mengendalikan diri. Konsentrasi dibutuhkan siswa dalam mengikuti pembelajaran. Meditasi dibiasakan oleh guru dengan menyadari bahwa meditasi adalah bagian dari Dhamma, sehingga dengan mengajarkan meditasi pada siswa itu berarti guru mengajarkan Dhamma kepada siswa. Untuk mencapai tujuan tersebut di atas perlu adanya kegiatan pembiasaan meditasi pada siswa. Pihak sekolah melalui kepala sekolah, guru menyelenggarkan program rutin meditasi harian atau mingguan. Pembiasaan meditasi pada siswa memberi efek positif pada siswa. Sikap siswa terkendali dan mampu menunjukkan sikap batin yang konsentrasi dan ketenangan siswa sudah mulai terbentuk, namun masih dalam proses. Sebagian siswa juga dapat menjaga konsentrasi pada saat pembelajaran, mampu mengendalikan diri dengan cara melatih kesabaran saat menghadapi situasi yang tidak diharapkan oleh siswa.

\section{Pemandu Meditasi}

Di SD Dharma Putra selain guru Pendidikan Agama Buddha, ada juga Atthasilani yang memandu meditasi saat Pendidikan Agama Buddha. Pemandu meditasi di SD Insan Teratai dan SD Sinar Dharma adalah audio panduan meditasi yang setiap hari diulang-ulang. Guru Pendidikan Agama Buddha di Atisa Dipamkara dalam membimbing meditasi dengan terlebih dahulu menjelaskan manfaat meditasi menggunakan kata-kata yang mudah dipahami, lalu memperlihatkan gambar sikap meditasi yang benar kepada 
siswa setelah itu memulai mengajak siswa bermeditasi. Guru Pendidikan Agama Buddha di SD Mutiara Bangsa membiasakan meditasi melalui pelajaran Pendidikan Agama Buddha khususnya pada kelas enam karena berdasarkan kurikulum pendidikan yang berlaku saat ini, pada mata pelajaran kelas enam terdapat materi meditasi sehingga guru memiliki kesempatan untuk mengajarkan meditasi kepada siswa. Guru-guru di SD Dharma Putra turut serta dalam meditasi bersama yang dilaksanakan di halaman sekolah, guru menjadi model meditasi yaitu duduk tegap, rileks dan tenang. Pengulangan kata-kata positif dilakukan oleh guru-guru di SD Sinar Dharma dengan cara memutar audio panduan meditasi yang berisi kata-kata positif.

\section{Tempat Pelaksanaan Meditasi}

Siswa SD Tri Ratna, SD Sinar Dharma mengawali kegiatan pembelajaran dengan bermeditasi di ruang kelas masing-masing, dengan siswa SD Tri Ratna kadang-kadang bermeditasi di ruang cetiya. Siswa SD Dharma Putra mengawali kegiatan pembelajaran di kelas pada tiap hari Selasa, Rabu, dan Kamis; dan di halaman sekolah pada hari Senin dan Jumat, sedangkan di harihari tertentu siswa bermeditasi di ruang cetiya. SD Insan Teratai mengawali kegiatan pembelajaran dengan Silent Sitting di ruang aula, di halaman, dan di kelas. Siswa SD Atisa Dipamkara bermeditasi di ruang Dhamma Class.

\section{Durasi Meditasi}

SD Atisa Dipamkara, guru Pendidikan Agama Buddha menentukan durasi meditasi untuk kelas kecil kurang dari lima menit, sedangkan untuk kelas 6 lebih lama, karena menyesuaikan materi meditasi yang salah satu aktivitas pembelajarannya dilakukan dengan praktik. Durasi meditasi SD Mutiara Bangsa dibedakan untuk kelas kecil dan kelas besar, pada kelas enam durasi meditasi lebih lama karena siswa mempraktikkan berbagai postur atau sikap tubuh meditasi yaitu duduk, berdiri, berjalan, dan berbaring. Durasi meditasi rutin di SD Dharma Putra dilakukan kurang dari 5 menit. Meditasi rutin untuk semua siswa SD Sinar Dharma dilakukan sekitar 5-10 menit, namun untuk siswa yang butuh bimbingan dan konseling berdurasi lebih lama yaitu 15 menit dari pukul 06.45-07.00 pagi. Silent Sitting di SD Insan Teratai adalah 15 menit, namun akan dievaluasi berdasarkan keluhan siswa.

\section{Media Pembiasaan Meditasi}

Media yang digunakan untuk memandu meditasi di SD Insan Teratai dan SD Sinar Dharma adalah audio panduan suara yang diiringi musik instrumen, siswa bermeditasi dengan mendengarkan arahan dari suara panduan meditasi yang diiringi musik instrumen. Guru-guru di SD Sinar Dharma memutar audio panduan meditasi dengan menggunakan handphone dan laptop. Bel digunakan oleh guru Pendidikan Agama Buddha di SD Tri Ratna, SD Atisa Dipamkara, dan SD Mutiara Bangsa. Di SD Dharma Putra, pada saat meditasi bersama juga diperdengarkan suara untuk memandu kegiatan meditasi. 
Teknik Meditasi Siswa

Aktivitas siswa saat meditasi antara lain duduk hening, duduk di lantai cetiya, dan duduk di kursi kelas. Siswa duduk tegap, tangan diletakkan di pangkuan, dan mata dipejamkan. Meditasi dengan cara duduk di lantai dilakukan oleh siswa bila kegiatan meditasi di ruang cetiya, aula, halaman, atau di ruang Dhamma Class. Meditasi dengan duduk di kursi dilakukan bila kegiatan dilakukan di ruang kelas. Meditasi yang dilakukan dengan berdiri, berjalan, berbaring dilakukan di SD Tri Ratna, SD Mutiara Bangsa terutama sebagai bagian praktik materi pembelajaran kelas enam. Meditasi dilakukan untuk menjaga keheningan diri, memfokuskan pada objek meditasi dan arahan atau panduan meditasi. Teknik meditasi yang digunakan adalah pemusatan konsentrasi.

\section{Objek Meditasi Siswa}

Siswa diajarkan untuk memusatkan batin pada objek meditasi. Objek meditasi yang digunakan siswa adalah pernafasan, cinta kasih, dan perenungan. Meditasi dengan objek pernafasan dilakukan siswa dengan fokus pada nafas masuk dan keluar. Meditasi dengan objek cinta kasih dilakukan dengan cara mengembangkan pikiran-pikiran yang baik kepada semua orang, mendoakan agar semua makhkuk hidup bahagia, mulai dari lingkungan terdekat yaitu diri sendiri, orangtua, saudara, teman hinggga ke semua makhluk. Meditasi dengan perenungan dilakukan dengan cara memfokuskan diri pada suara panduan meditasi ataupun yang berisi kalimat-kalimat positif yaitu kalimat penguatan perilaku yang sesuai dengan sila atau moralitas.

Beberapa sekolah konsisten dalam memilih objek meditasi terutama yang telah memiliki panduan meditasi baku yaitu SD Insan Teratai, SD Dharma Putra, dan SD Sinar Dharma. Sekolah yang tidak memiliki panduan meditasi baku, guru Pendidikan Agama Buddha berinisiatif menggunakan objek meditasi berbeda-beda, namun mudah dipahami anak dan guru pembimbing.

Objek meditasi dipilih berdasarkan pertimbangan bahwa objek tersebut lebih mudah dipahami dan dipraktikkan siswa, sesuai dengan kebiasaan sehari-hari, lebih cocok dengan anak, anak lebih mudah dipandu, guru memandu lebih mudah, atau karena ada materi meditasi pada kelas 6. Meditasi dengan objek pernafasan mudah diikuti siswa karena saat meditasi siswa berkonsentrasi pada nafas masuk dan nafas keluar. Guru pun mudah memandu dan mengarahkan siswa pada meditasi dengan objek pernafasan. Meditasi dengan objek cinta kasih dipilih guru karena mudah dalam memandu dan dapat disesuaikan dengan aktivitas siswa sehari-hari dengan guru memandu siswa untuk mengembangkan cinta kasih kepada diri sendiri, orangtua, teman, saudara hingga ke semua makhluk. Khusus siswa kelas enam yang memperoleh materi meditasi, praktik merupakan metode pembelajaran yang dipilih guru agar siswa mengalami langsung berbagai macam postur atau sikap tubuh saat meditasi, mengalami hambatan yang dialami saat meditasi dan cara mengatasinya, serta manfaat dari praktik latihan meditasi. 
Faktor-Faktor Penghambat Meditasi

Kendala, hambatan dan tantangan dari kegiatan pembiasaan meditasi adalah perilaku siswa. Perilaku kurang tepat yang ditunjukkkan siswa saat meditasi misalnya adalah anak usil dengan teman sebelah atau bermain sendiri saat sesi meditasi. Untuk itu, pedampingan siswa menjadi hal yang mutlak dilakukan agar meditasi dapat terlaksana dengan baik. Beberapa sikap kurang baik siswa saat bermeditasi dikarenakan minat terhadap meditasi kurang, sehingga kurang fokus dengan arahan atau panduan, serta objek meditasi yang dilakukan. Faktor eksternal yang mengganggu atau menghambat pelaksanaan meditasi adalah situasi yang kurang tepat. Misalnya di SD Atisa Dipamkara siswa kurang fokus saat meditasi karena lokasi ruangan meditasi dekat dengan lorong kelas sehingga banyak siswa atau guru lewat ketika istirahat atau pergantian jam.

Guru piket di SD Insan Teratai mengatasi siswa yang sedang bermeditasi dengan menasehati secara berbisik agar siswa lain tidak terganggu. Kepala SD Dharma Putra menyarankan cara mengatasi masalah dengan mengadakan kegiatan pembimbingan dan pelatihan sehingga diketahui jenis hambatan meditasi siswa dan cara mengatasinya, serta siswa memiliki keterampilan meditasi dengan benar. Guru PAB Atisa Dipamkara terus-menerus memberikan penjelasan manfaat meditasi bagi siswa sembari mempraktikkan sehingga siswa dapat merasakan manfaatnya. Bila terjadi kejenuhan terhadap meditasi, guru PAB SD Tri Ratna mengganti metode atau kegiatan meditasi, baik dari segi teknik, objek ataupun postur atau sikap tubuh.

\section{Evaluasi Kegiatan Meditasi}

Bentuk evaluasi kegiatan atau program meditasi dilakukan yayasan, kepala sekolah atau pun guru. Di SD Atisa Dipamkara dilakukan dengan yayasan melakukan supervisi pada kegiatan Dhamma class serta dengan mengamati aktivitas meditasi kemudian memberikan saran atau masukan. Guru atau pembimbing meditasi melakukan evaluasi dengan cara mengamati dan memperbaiki sikap tubuh siswa saat meditasi. Di SD Dharma Putra, Kepala Sekolah dan guru mengamati langsung kegiatan meditasi yang dilakukan oleh siswa. Sedangkan di SD Insan Teratai, evaluasi dilakukan guru piket dengan cara mengamati kemudian memberi tindakan bila ada siswa yang kurang tepat saat bermeditasi, guru bertanya kepada siswa terkait hambatan, kendala, atau efek meditasi meditasi.

\section{Simpulan}

Berdasarkan hasil penelitian dan pembahasan dapat disimpulkan bahwa pembiasaan meditasi merupakan program dari kebijakan yayasan, kepala sekolah atau guru Pendidikan Agama Buddha. Nama kegiatan meditasi yang dikenalkan di antaranya silent sitting, duduk hening, dhamma class. Pembiasaan meditasi dilakukan dengan siswa bermeditasi secara rutin; guru Pendidikan Agama Buddha atau guru piket menjadi pemandu langsung; pelaksanaan meditasi dilakukan di kelas, cetiya, ruang Dhamma class, aula, atau halaman 
sekolah. Meditasi dilakukan dengan berkonsentrasi pada objek meditasi atau mendengarkan kalimat-kalimat positif; durasi meditasi antara 3-15 menit sesuai dengan tingkatan kelas dan tujuan meditasi. Media yang digunakan sebagai panduan meditasi adalah audio panduan meditasi, music instrument, bell, dan gambar slide. Objek meditasi yang digunakan adalah pernafasan, cinta kasih, dan perenungan. Evaluasi kegiatan meditasi dilakukan yayasan, kepala sekolah, guru kepada siswa.

\section{Daftar Pustaka:}

Buddhaghosa. Tanpa Tahun. Visudhimagga: The Path of Purification. Translated from the Pali by Nánamoli. Sri Lanka: Buddhist Publication Society.

Burns, Douglas M. 1994. Buddhist Meditation and Depth Psychology. Sumber online:

http://www.accesstoinsight.org/lib/authors/burns/wheel088.html diakases pada tanggal 7 Maret 2017.

Desmita. 2010. Psikologi Perkembangan Peserta Didik. Bandung: PT Remaja Rosdakarya.

Lay, U Ko. 2000. Guide to Tipitaka. Alih bahasa Lanny Anggawati dan Wena Cintiawati. Klaten: Vihara Bodhivamsa.

Nanamoli. 2001. Khuddakapatha Kitab Suci Agama Buddha,, Seri 1, 2, dan 3. Judul Asli The Miror Readings (Khuddakapatha), Alih Bahasa Lanny Anggawati dan Wena Cintiawati. Klaten: Vihara Bodhivamsa.

Notoatmodjo, Soekidjo. 2012. Promosi kesehatan dan Perilaku Kesehatan. Jakarta: Rineka cipta.

Shaw, Sarah. 2006. Buddhist Meditation An Anthology of Texts. New York: Routledge Critical Studies in Buddhism.

Story, Francis. 1995. Buddhist Meditation. Sumber online: http://www.accesstoinsight.org/lib/authors/story/bl015.html diakses pada tanggal 24 Agustus 2017.

Davids, T. W. Rhys dan William Stede. 2009. Pali-English Dictionary. The Pali Text Society's.

The Khuddakapatha: Khp 1-9 Manggala Sutta. translated from the Pali by Thanissaro http://www.accesstoinsight.org/tipitaka/kn/khp/khp.19.than.html\#khp-5

Vijja-bhagiya Sutta: A Share in Clear Knowing, translated from the Pali by Thanissaro. $1998 . \quad$ Sumber online: http://www.accesstoinsight.org/tipitaka/an/an02/an02.030.than.html diakses pada tanggal 24 Agustus 2017. 
ISSN: 2442-6016

Volume. 5, No.1, Edisi Juni 2018

www.stabn-sriwijaya.ac.id. 